\title{
"JUMP": GAME SIMULASI OLAHRAGA BERBASIS VIRTUAL REALITY DENGAN SENSOR ACCELEROMETER
}

\author{
${ }^{1}$ Joe Yuan Mambu, ${ }^{2}$ Andria Kusuma Wahyudi, and ${ }^{3}$ Gerry Hezky \\ 1,2,3 Program Studi Sistem Informasi, Universitas Klabat, Airmadidi \\ E-mail: ${ }^{1}$ ljoeyuan.mambu@unklab.ac.id, ${ }^{2}$ andriawahyudi@unklab.ac.id, ${ }^{3}$ gerryhezky@gmail.com
}

\begin{abstract}
Health is an important factor for every human being. Good health can be maintained through a regular diet and exercise. Sports is one of the physical activities can fulfill these needs. By exercising, a person can minimize the risk of developing an illness. The simplest exercise that can be done is jumping, jumping is an exercise that can be done any day, by jumping the person can burn calories and pumping blood. With the development of technology, the researchers designed a jumping game that can be used by users who did not have time to go to a sporting place. The game uses an Android platform smartphone and accelerometer sensors found on smartphones with virtual reality technology. Virtual Reality is a technology that allows users to interact with the virtual world. This game can display estimation of how many calories are burned while playing games and displaying tall buildings. This game is run by using the VR Headset and is controlled by the user with a vertical jump and running in place. The research aimed to serve as a proof of concept for play and exercise using a smartphone and accelerometer censor and not including evaluation in using it.
\end{abstract}

Keywords: Health, Exercise, Smartphone, Andorid, Accelerometer, Virtual Reality, VR Headset.

\begin{abstract}
Abstrak
Kesehatan merupakan kebutuhan utama bagi setiap manusia. Kesehatan sendiri bisa diperoleh dengan cara menjaga pola makan dan olahraga secara teratur. Olahraga adalah salah satu aktivitas fisik yang baik bagi kesehatan dan kebugaran tubuh. Dengan berolahraga, pengguna dapat meminimalisir resiko terserang penyakit. . Olahraga yang paling sederhana yang dapat dilakukan adalah melompat, melompat merupakan olahraga yang setiap hari dapat lakukan, dengan melompat pengguna dapat membakar kalori yang disertai dengan peningkatan aktivitas kerja jantung memompa darah. Dengan berkembangnya zaman dan teknologi, peneliti merancang sebuah game melompat yang dapat digunakan oleh pengguna yang tidak sempat untuk ke tempat olahraga. Game tersebut menggunakan smartphone ber-platform android serta sensor acceleromter yang terdapat pada smartphone dengan teknologi virtual reality. Virtual Reality adalah teknologi yang membuat pengguna bisa berinteraksi dengan dunia Virtual. Game ini dapat menampilkan informasi tentang berapa banyak kalori yang terbakar saat bermain game dan menampilkan gedung-gedung tinggi. Game ini dijalankan dengan menggunaka VR Headset dan dikendalikan oleh pengguna dengan cara berjalan dan melompat-lompat. Hasil penelitian ini adalah berupa output program yang membuktikan konsep bermain dan berolahraga menggunakan smartphone dan sensor akselerometer, belum termasuk evaluasi penggunaan.
\end{abstract}

Kata Kunci: Kesehatan, Olahraga, Smartphone, Andorid, Accelerometer, Virtual Reality, VR Headset

\section{Pendahuluan}

Kesehatan merupakan kebutuhan utama bagi setiap manusia. Kesehatan sendiri bisa diperoleh dengan cara menjaga pola makan dan olahraga secara teratur (Azizah, Akhriza, \& Prasetyo, 2017). Namun karena kesibukan yang terjadi pada masyarakat, sehingga kurangnya kesadaran untuk berolahraga secara teratur. Olahraga adalah salah satu aktivitas fisik yang baik bagi kesehatan dan kebugaran tubuh. Dengan berolahraga, pengguna dapat meminimalisir resiko terserang penyakit. Dengan berolahraga pula, 
pengguna dapat menurunkan berat badan, dan menjaga berat tubuh agar tetap stabil dan ideal (Fitriyanti, 2013). Olahraga yang paling sederhana yang dapat dilakukan adalah melompat, melompat merupakan olahraga yang setiap hari dapat lakukan, dengan melompat pengguna dapat membakar kalori yang disertai dengan peningkatan aktivitas kerja jantung memompa darah (Olajuwon, 2017) .Dengan berkembangnya zaman dan teknologi, peneliti merancang sebuah game melompat yang dapat digunakan oleh pengguna yang tidak sempat untuk ke tempat olahraga. Game tersebut menggunakan smartphone ber-platform android (Hartanto, 2014) serta sensor acceleromter yang terdapat pada smartphone dengan teknologi virtual reality, sehingga pengguna dapat menggunakan game ini apabila tidak sempat untuk ke tempat olahraga. Game ini dapat menampilkan informasi tentang berapa banyak kalori yang terbakar saat bermain game. Berdasarkan latar belakang diatas, peneliti merancang game jump exercise berbasis virtual reality dengan accelerometer sensor. Melalui penelitian ini, peneliti berharap game jump exercise ini dapat mempermudah pengguna bermain sambil berolahraga.

\section{Metode Penelitian}

Penelitian menggunakan metode Spiral dalam pembuatan game jump exercise virtual reality dengan sensor accelerometer. Metode Spilar merupakan salah satu metode pengulangan secara alamiah dari proses model Prototyping dengan pengontrolan secara sistematik dengan aspek-aspek proses model Waterfall (Pressman, 2010). Peneliti menggunakan metode ini dikarenakan model spiral adalah metode yang menggabungkan kelebihan dari metode Prototyping dan metode Watelfall.

\section{Instrumentasi}

Pada bagian ini menjelaskan tentang bagaimana cara untuk menyelesaikan penelitian ini dalam membuat aplikasi, dimana teknik yang digunakan dalam penelitian ini adalah pengumpulan data, perancangan, pemodelan, pengkodean, dan implementasi, dimana dapat dijelaskan dengan subsection berikut :

\section{Pengumpulan Data}

Pada tahap ini peneliti mengumpulkan data tentang pembuatan game dari buku Mudah membuat Game Augmented Reality dan Virtual Reality dengan menggunakan tools Unity 3D dan artikel-artikel yang terkait dengan penelitian ini.

Perancangan
Pada tahap ini peneliti menentukan objek gedung yang akan ditampilkan didalam aplikasi. Kemudian peneliti merancangkan bagaimana aplikasi ini akan digunakan dan menganalisi tampilan, dan bahasa pemograman yang akan digunakan.

Pemodelan

Tahap ini berfungsi untuk menganalisa dan memperkirakan pembuatan aplikasi sehingga nantinya dapat dirancang sebuah model aplikasi yang dibuat oleh peneliti.

\section{Pengkodean}

Tahap ini peneliti melakukan pengkodean dengan bahasa pemograman $\mathrm{C \#}$ yang terdapat pada aplikasi Unity.

\section{Implentasi}

Peneliti akan mengimplementasi dan melakukan uji coba aplikasi yang telah dibuat kemudian menganalisa hasil dari uji coba apakah sesuai dengan rencana awal atau tidak. Jika sesuai dengan perencanaan maka aplikasi akan diserahkan kepada pengguna.

\section{Kalori}

Kalori adalah setiap satuan energi yang bisa didapatkan dari mengkonsumsi makanan. Setiap jenis makanan tertentu menghasilkan kalori dalam jumlah yang berbeda. Jumlah energi yang dibutuhkan oleh manusia berbeda-beda, tergantung dari ukuran tubuh, jenis kelamin, usia, suhu tubuh, akivitas, dan status gizi.

Metabolic Equivalent Of Task

Metabolic Equivalent Of Task (MET) menunjukkan intensitas aktivitas fisik. MET digunakan untuk memperkirakan jumlah oksigen yang digunakan oleh tubuh selama aktivitas fisik $1 \mathrm{MET}=$ (energi (oksigen) yang digunakan oleh tubuh) (Jette, Sidney, \& Blümchen, 1990).

Dengan meningkatnya aktivitas, lebih banyak oksigen yang dikonsumsi dan tingkat MET meningkat.

$<3 \mathrm{MET}=$ Aktivitas fisik intensitas ringan .

3 to $6 \mathrm{MET}=$ Aktivitas fisik intensitas sedang. $6>$ MET $=$ Aktivitas fisik intensitas kuat.

Rumus untuk menjumlahkan MET : \{ (MET x Weight) x 3.5ml oxygen $\}$

Berjalan di tempat dan melompat termasuk dalam MET moderate (intensitas sedang) dan vigorous (intensitas tinggi), yaitu tingkat MET 
mulai dari 3 to 6 dan $6>$ (Ainsworth, et al., 2000).

\section{Perhitungan Kalori}

Teori dasar penghitungan kalori yang terbakar saat berolahraga. Olahraga membutuhkan energi yang dikenal dalam satuan kilo kalori. Sumber energi ini berasal dari lemak atau dari glikogen. Banyak faktor yang mempengaruhi kalori yang terbakar selama olahraga. Yang pertama dan terpenting adalah adaptasi tubuh kita, karena seiring dengan adaptasi tubuh terhadap aktivitas olahraga, maka tubuh lama kelamaan akan lebih efisien membakar kalori. Sehingga dengan aktivitas olahraga yang sama tubuh lama kelamaan akan membakar kalori yang lebih sedikit. Faktor kedua adalah volume otot. Karena otot selalu aktif secara metabolisme, maka makin tinggi volume otot, semakin banyak juga kalori yang terbakar. Faktor-lain adalah berat badan, intenstias olahraga dan kondisi metabolisme tubuh itu sendiri.

Dalam penelitian, setiap gerakan olahraga dicari nilai dari MET (metabolic equivalent of task) yang merupakan angka perkiraan kalori yang terbakar saat melakukan aktivitas olahraga tersebut dalam waktu tertentu, kemudian dibandingkan dengan perkiraan volume massa otot tubuh. Selain untuk mencari kalori yang terbakar ketika berolahraga, kita dapat juga menggunakan perhitungan yang sama untuk menghitung berapa kalori yang terbakar untuk aktivitas sehari-hari. Rumus dasarnya adalah sebagai berikut (Balady, 2000):

$\mathrm{ECM}=0.0175 \times$ MET $\times$ Weight $(\mathrm{kg})$

$\mathrm{ECS}=0.0175 \times$ MET $\times$ Weight $(\mathrm{kg}) / 60$

Ket :

$\mathrm{ECM}=$ Estimasi Exercise Calories "Cal" (per menit)

ECS = Estimasi Exercise Calories "Cal" (per detik)

Weight $=$ Berat Badan

MET $=$ Metabolic Equivalent Of Task

\section{Lingkungan Perancangan Hardware dan Software}

Peralatan yang digunakan dalam penelitian ini adalah semua yang berhubungan dengan perangkat keras dan perangkat lunak untuk membangun sebuah aplikasi game jump exercise berbasis virtual reality dengan accelerometer sensor.

1. Laptop Asus X555Q

2. Unity 2018 3.3fl :

Aplikasi yang digunakan untuk membuat game jump exercise

3. C\# : Bahasa program yang digunakan dalam pembuatan game jump exercise.

\section{Analisa Sistem}

Dalam membangun sistem pada penelitian ini, peneliti menggunakan Unfied Modelling Language (UML) diagram yang terdiri atas Use Case Diagram dan Sequence Diagram dengan masing-masing diagram sebagai berikut :

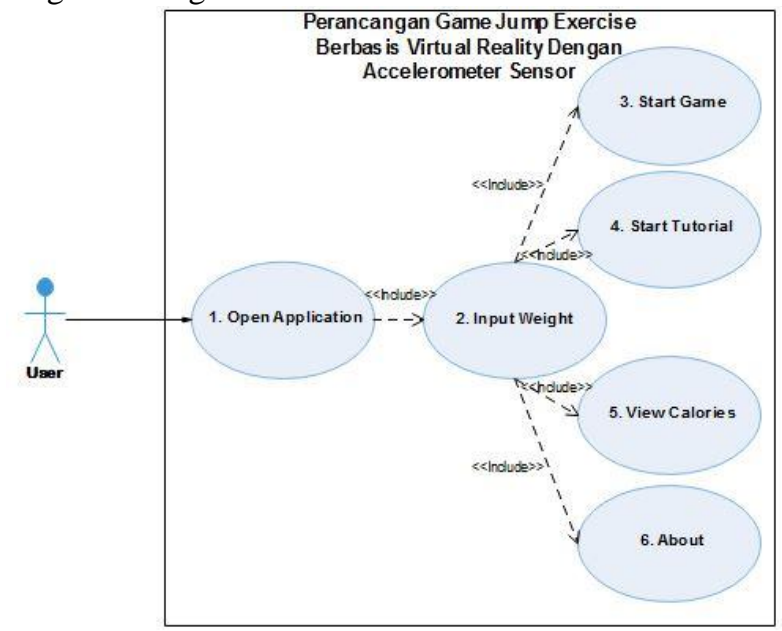

Gambar 1. Use Case Diagram Game Jump

Exercise

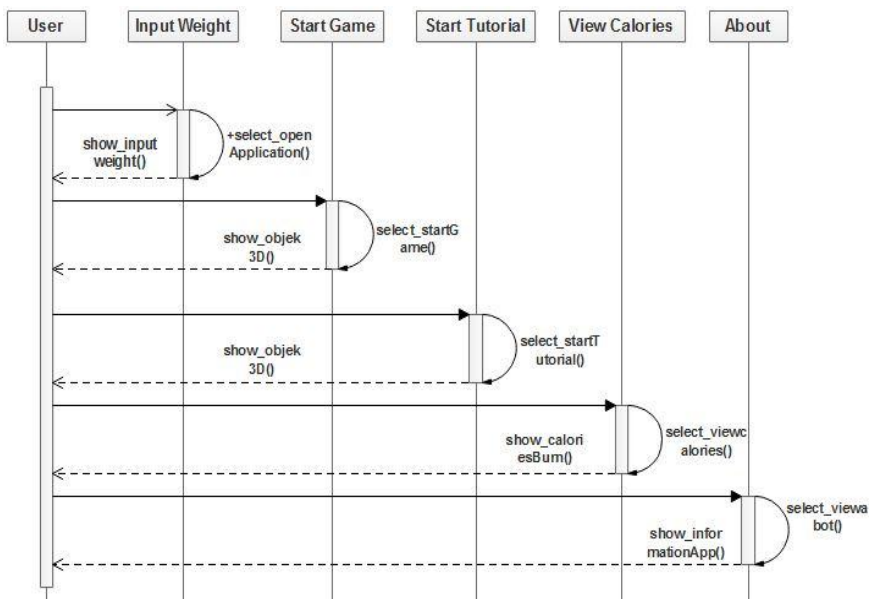

Gambar23. Sequence Diagram Game Jump Exercise

Pada Use Case Diagram 1 diatas menjelaskan bagaimana user mengakses game jump exercise, dimana user memulai dengan membuka aplikasi, kemudian memasukan berat badan, setelah itu user dapat memilih main game atau melihat tutorial terlebih dahulu.

Gambar 2 merupakan sequence diagram proses pada penelitian ini. Pengguna akan membuka aplikasi kemudian memilih menu yang di dalam game. 


\section{Hasil dan Pembahasan}

Pada gambar 3 ini menjelaskan secara umum kerangka konseptual aplikasi. Pada tahap awal , pengguna membuka aplikasi dan meletakan smartphone kedalam VR case. Langkah kedua yaitu pengguna memakai VR case dan pengguna akan langsung dapat masuk kedalam game tersebut. Langkah ketiga setelah itu pengguna akan memilih di Main Menu tombol Play yang akan membawa pengguna ke dalam game. Langkah keempat pengguna akan berlari dan melompat (berlari dan melompat ditempat) kemudian lompatan yang dilakukan oleh pengguna akan direspon oleh sensor accelerometer yang akan membuat lompatan terjadi didalam game.

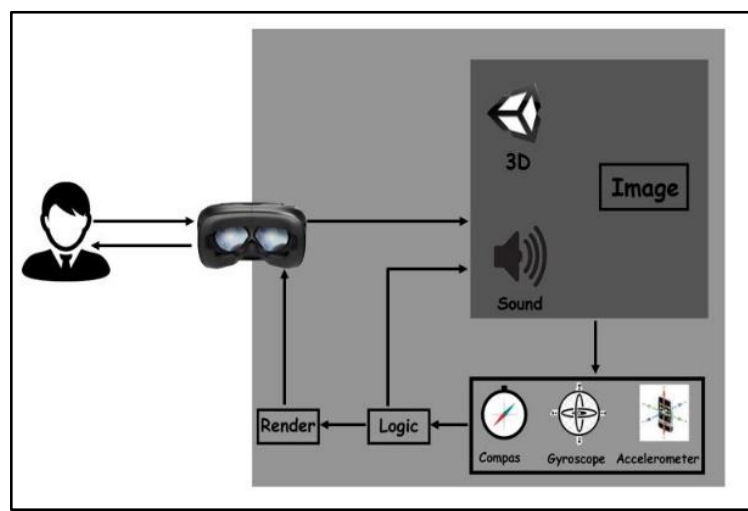

Gambar 3. Kerangka Konseptual Aplikasi

\section{Cara Memainkan}

Pengguna bias mengeenakan VR Headset dan memilih menu sebelum mulai bermain. Untuk berinteraksi pemain bisa berjalan dan melompat ditempat untuk berjalan dan melompat di dalam game. Gerakan berjalan dan melompat akan dideteksi oleh sensor accelerometer dan membuat karakter bergerak berjalan atau meloncat seperti yang di ilustrasikan oleh Gambar 4.

Setiap gerakan akan dihitung estimasi kalori yang terbakar dan di display di layar pemain.

Disarankan pemain untuk memainkan game ini di ruangan tertutup dan bebas rintangan atau objek di lantai untuk radius 5 meter agar menghindari gangguan atau bahkan kecelakaan.

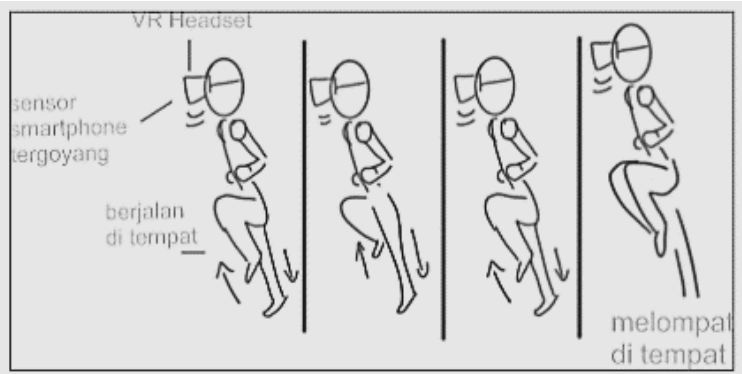

Gambar 4. Ilustrasi cara bermain

\section{Perangkat Antarmuka}

Tampilan permainan dimulai dengan input berat badan. Dimana variable berat badan ini akan digunakan untuk penghitungan estimasi kalori terbakar. Setelah itu akan masuk di main menu seperti yang terlihat di gambar 5. Untuk memilih menu pengguna bisa memencet tombol dengan jari atau bisa mengposisikan pointer ke tombol untuk 3 detik.

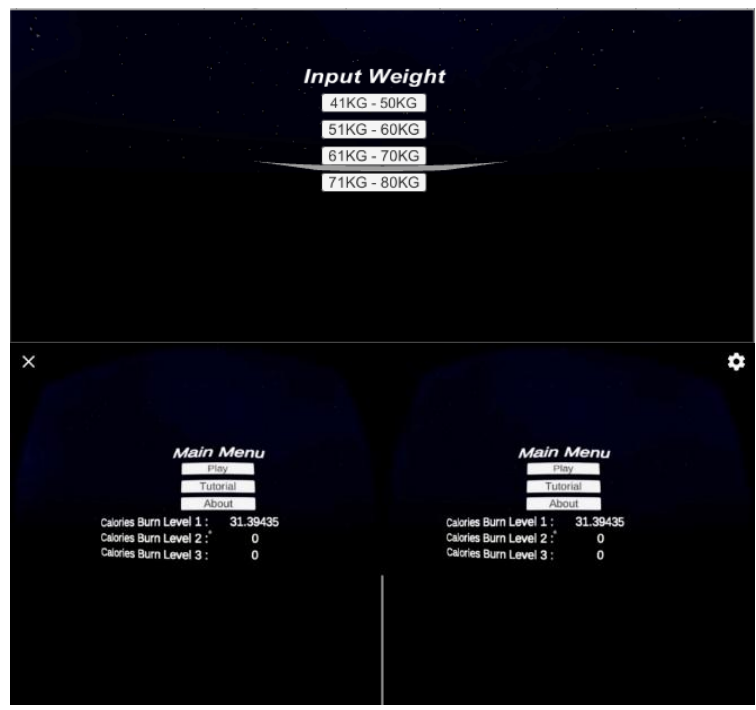

Gambar 5. Input berat badan dan menu awal.

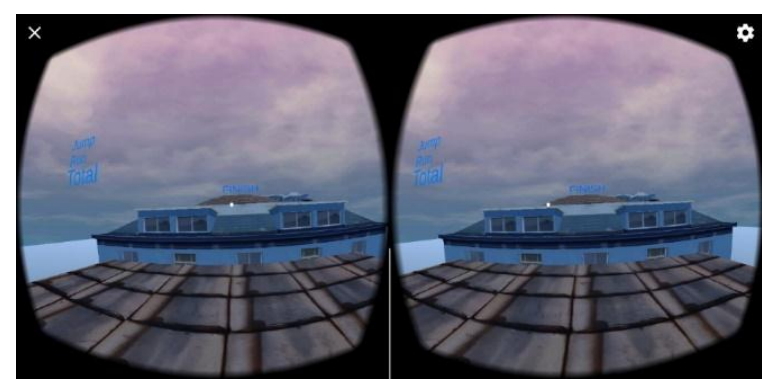




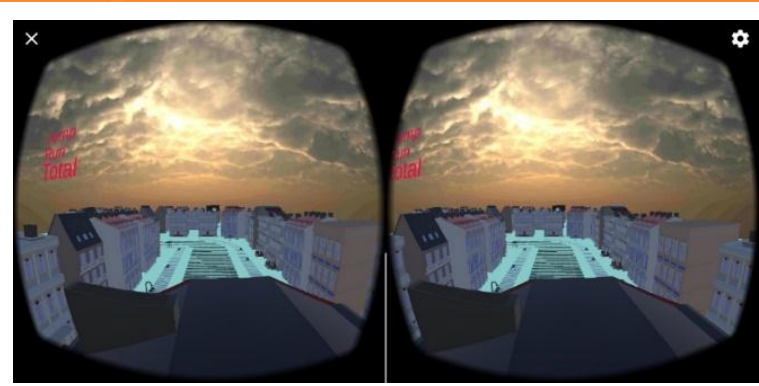

Gambar 6. Tampilan Game

Gambar 6 menunjukkan tampilan permainan. Pemain seolah berada di atas gedung dan harus melompat dari gedung ke gedung. Tampilan jumlah kalori dan lompatan terlihat di sebelah kiri.

\section{Kesimpulan}

Berdasarkan kesimpulan ini, maka dapat disimpulkan:

1. Kelebihan Virtual Reality (VR) adalah sebuah teknologi yang membuat pengguna dapat berinteraksi dengan lingkungan yang ada dalam dunia maya yang disimulasikan oleh komputer, sehingga pengguna merasa berada di dalam lingkungan tersebut.

2. Aplikasi ini menampilkan gedung-gedung tinggi yang akan dilewati oleh pengguna dengan cara berlari dan melompati gedung tersebut.

3. Aplikasi ini dijalankan pada device yang menggunakan sistem operasi Android dengan versi minimal Andorid 5 (Lolipop) menggunakan VR Headset dan dikendalikan oleh pengguna.

\section{Saran \& Penelitian Selanjutanya}

Pada penelitian ini, masih perlu adanya penyempurnaan pada aplikasi sehingga peneliti memberikan saran untuk pengembang selanjutnya dari penelitian ini yaitu:

Dari sisi gameplay effect:

1. Diperlukan penelitan lanjut untuk meneliti durasi dan frekuensi yang aman dan bisa dianjurkan untuk memainkan game dengan mengukur efek game terhadap Pre Frontal Cortex (Addiction Risk)

2. Juga diperlukan evaluasi terhadap resiko neck injury mengingat game ini menggunakan $v r$ headset (beban ke leher/kepala) dan melompat.

3. Menambahkan warning pada game untuk keamanan dalam bermain dan efek-efek lain dari bermain (setelah mendapatkan hasil evaluasi di nomor $1 \& 2$ di atas).
1. Aplikasi ini seharusnya dibuat juga dalam sistem operasi lain seperti iOS.

2. Adanya penambahan sensor pada aplikasi ini agar perhitungan kalori yang didapat bisa lebih akurat.

3. Adanya penambahan pada tampilan antar muka agar lebih menarik.

\section{References}

Ainsworth, B., Haskell, W., Whitt, M., Irwin, M., Swartz, A., \& S, S. (2000). Compendium of physical activities: an update of activity codes and MET intensities. Medicine and science in sports and exercise, S498-S504.

Azizah, F. N., Akhriza, T. M., \& Prasetyo, A. (2017). Aplikasi Android Untuk Membantu Program Diet Berbasis Android. Teknik Informatika STIMIK Pradnya Paramita, Malang, 1(1), 588.

Balady, G. (2000). ACSM's guidelines for exercise testing and prescription. American College of Sports Medic.

Fitriyanti, A. D. (2013). Aplikasi Penghitung Kalori Terbakar Saat Berolahraga Sepeda Menggunakan Global Possition System (GPS) Berbasis Android. Jurnal Teknologi Informasi, 4(2), 1.

Hartanto, B. (2014). Aplikasi Latihan Beban Berbasis Android. Eprint UMM Indonesia, 1(1), 1.

Jette, M., Sidney, K., \& Blümchen, G. (1990). Metabolic equivalents (METS) in exercise testing, exercise prescription, and evaluation of functional capacity. Clinical Cardiology, 555-565.

Olajuwon, M. D. (2017). Aplikasi Pendeteksi Kalori Terbakar Dengan Smartphone Menggunakan Sensor Accelerometer dan Pedometer. Jurnal Teknik Informatika Universitas Islam Sunan Gunung Djati, Bandung, 4(1), 1.

Pressman, R. S. (2010). Software Engineering 7th Edition. New York: McGraw-Hill, 45.

Dari sisi teknis: 